\title{
Amplified Fluorescent Detection of Mercuric Ions by Conjugation of the ThT-induced G-Quadruplex Based Hybridization Chain Reaction
}

\author{
Tianxiao Chen, Shuzhen TAn, ${ }^{\dagger}$ Wei LI, ${ }^{\dagger}$ and Yuqing ZHU \\ School of Chemistry and Biological Engineering, Changsha University of Science and Technology, \\ Changsha 410004, China
}

\begin{abstract}
A sensitive fluorescent method for the detection of $\mathrm{Hg}^{2+}$ was developed based on triple-helix molecular switch (THMS)induced hybridization chain reaction (HCR) amplification. THMS was composed of a T-rich mercury-specific probe and an initiator probe, designed by the Watson-Crick and Hoogsteen base pairings and employed as a signal trigger. Two hairpin probes containing the G-quadruplex sequence were used as signal amplification elements. In the presence of $\mathrm{Hg}^{2+}$, the $\mathrm{T}-\mathrm{Hg}^{2+}-\mathrm{T}$ mismatch resulted in disassembling the THMS and releasing the initiator probe. One of the hairpins was opened by the released initiator probe, which triggered a successive cross-opening of two hairpins based the strand displacement principle, resulting in the formation of long-chain DNA with multiple G-quadruplex. When thioflavin T (ThT), a fluorophore, was bound to the G-quadruplex, an obvious fluorescence enhancement would occur. This sensing system enabled the highly sensitive and selective detection of aqueous $\mathrm{Hg}^{2+}$ with a limit-of-detection of $10.2 \mathrm{pM}$.
\end{abstract}

Keywords Hybridization chain reaction, mercury, triple-helix molecular switch, G-quadruplex, thioflavin T

(Received May 26, 2017; Accepted August 14, 2017; Published December 10, 2017)

\section{Introduction}

Mercury is considered to be one of the most alarming metals because of its highly toxicity and persistent bioaccumulation. ${ }^{1,2}$ Mercury usually exists in different forms including metallic, ionic and the organic/inorganic complexes, ${ }^{3}$ it can be transmitted to the human body through the food chain and accumulated in the body, resulting in chronic poisoning. Even a small amount of $\mathrm{Hg}^{2+}$ can cause damage to human health. ${ }^{4-6}$ With an increase of the mercury ion concentration, it can cause a developmental delay, while lead to brain, nervous system, kidney, endocrine system damage and various cognitive and motion disorders. ${ }^{7-9}$ Therefore, developing a sensitive and effective analytical method of detecting the content of $\mathrm{Hg}^{2+}$ is particularly important

Commonly, traditional approaches for the detection of $\mathrm{Hg}^{2+}$ are as follows: atomic absorption/emission spectroscopy (AAS/AES), ${ }^{10-12}$ inductively coupled plasma mass spectrometry (ICP-MS), ${ }^{13-15}$ high performance liquid chromatography (HPLC), ${ }^{16,17}$ cold vapor atomic fluorescence spectrometry (CV-AFS). ${ }^{18-20}$ However, these detection methods are rather limited by some deficiencies, such as expensive apparatus and complex sample pretreatment. Because $\mathrm{Hg}^{2+}$ can specifically link two thymine bases and form a stable thymine- $\mathrm{Hg}^{2+}$-thymine $\left(\mathrm{T}-\mathrm{Hg}^{2+}-\mathrm{T}\right)$ mismatch in a DNA duplex, ${ }^{21}$ some novel methods based on the formation of the $\mathrm{T}-\mathrm{Hg}^{2+}-\mathrm{T}$ structure have been developed in order to overcome the limitations of traditional approaches. $^{22-28}$ For example, Kong's group ${ }^{22}$ utilized the

† To whom correspondence should be addressed. E-mail: tsz519@163.com (S. T); 787319629@qq.com (W. L.)
$\mathrm{T}-\mathrm{Hg}^{2+}-\mathrm{T}$ base pairs to trigger the formation of catalytically active G-quadruplex DNAzymes and developed the "turn-on" colorimetric sensors; Zeng's group ${ }^{26}$ constructed an electrochemical sensor for mercury detection in environmental samples by using mercury-specific oligonucleotides, three dimensional gold nanoclusters, and an anionic intercalator; Tang's group ${ }^{27}$ developed a fluorescent sensor for $\mathrm{Hg}^{2+}$ assay by using $\mathrm{Hg}^{2+}$ specific DNA functionalized gold nanoparticles (AuNPs) based on the formation of $\mathrm{T}-\mathrm{Hg}^{2+}-\mathrm{T}$ complex and the excellent quenching fluorescence property of AuNPs. However, those assays mentioned above suffer from one or more of the following disadvantages, such as low sensitivity, high cost, and complexity. Thus, a new sensing platform that can overcome these shortcomings is highly desirable.

Herein, a novel label-free and highly sensitive fluorescence assay depending on the triple-helix molecular switch (THMS)induced hybridization chain reaction (HCR) amplification was developed for the detection of $\mathrm{Hg}^{2+}$. Hybridization chain reaction (HCR), was first introduced by Dirk and Pierce. ${ }^{29}$ It can carry out the self assembly of two hairpins with overlapping partial complementarities into a long double-stranded DNA (dsDNA) spontaneously under mild conditions in the presence of an initiator probe, and can be used as a simple and effective method for signal amplification. Several detection methods for $\mathrm{Hg}^{2+}$ have been developed based on the combination of $\mathrm{HCR}$ with other tradiational detection methods, ${ }^{30-32}$ for example, Wang's group ${ }^{30}$ describe a colorimetric assay for mercury(II) ion based on a hybridization chain reaction (HCR) and the use of $\mathrm{Fe}_{3} \mathrm{O}_{4} @ \mathrm{Au}$ nanoparticles (NPs). Xiong's group ${ }^{31}$ developed an electrochemical biosensor for mercury(II) ion based on the exonuclease III (Exo III)-assisted target recycling and 
hybridization chain reaction (HCR) amplification strategies. Sui's group ${ }^{32}$ report a fluorescent strategy based on metalenhanced fluorescence (MEF) and hybridization chain reaction (HCR). THMS was designed according to the principle of Watson-Crick and Hoogsteen base pairings, and composed of a target specific aptamer flanked by two arm segments and a dual-labeled oligonucleotide serving as a signal transduction probe (STP). ${ }^{33,34}$ Aptamer/target binding results in the disassembling of the THMS and releasing the STP to achieve the purpose of detection. Compared with double-helix DNA molecular switches and molecular beacon-based signaling aptamers, the THMS presents distinct advantages, including sensitivity, high stability, preserved selectivity and original aptamer affinity. ${ }^{35}$ Recently, the THMS have been designed and adopted for the fluorescence, ${ }^{36,37}$ colorimetric $^{38}$ and electrochemical ${ }^{39}$ biosensing strategies.

In this work, a target specific aptamer in the above-mentioned THMS was replaced with a T-rich probe (a thymine-rich mercury-specific oligonucleotide flanked by two arm segments) for selectively binding mercury(II) ion. A dual-labeled oligonucleotide in the above-mentioned THMS was substituted for an initiator probe for triggering a hybridization event. Two hairpin probes $(\mathrm{H} 1, \mathrm{H} 2)$, which were functionalized at $5^{\prime}$ and $3^{\prime}$ ends of the stem regions with three-fourths and one-fourth of the G-quadruplex respectively, were used as signal-amplification elements. In the presence of $\mathrm{Hg}^{2+}$, the $\mathrm{T}-\mathrm{Hg}^{2+}-\mathrm{T}$ base pairings resulted in disassembling the THMS and releasing the initiator probe. One of the hairpins was opened by the released initiator probe, which triggered a successive cross-opening of two hairpins based the strand displacement principle, resulting in the formation of long-chain DNA with multiple G-quadruplex. Thioflavin T (ThT), a commercially available dye which could be selectively bound to the G-quadruplex structure with the result of fluorescence enhancement, ${ }^{40,41}$ was employed as the fluorophore to design a label-free THMS-HCR-based fluorescence sensor. Because the T-T base pair can only be stabilized by $\mathrm{Hg}^{2+}$, this platform has excellent selectivity and sensitivity for the detection of $\mathrm{Hg}^{2+}$.

\section{Experimental}

\section{Reagents and chemicals}

Thioflavin $\mathrm{T}$ and $\mathrm{Hg}\left(\mathrm{NO}_{3}\right)_{2}$ were purchased from SigmaAldrich (St. Louis, MO). Tris- $\mathrm{HNO}_{3}$ buffer $(25 \mathrm{mM}$, containing $400 \mathrm{mM} \mathrm{NaNO}, 20 \mathrm{mM} \mathrm{KNO}, 10 \mathrm{mM} \mathrm{Mg}\left(\mathrm{NO}_{3}\right)_{2}, \mathrm{pH}$ 6.5) was used for the fluorescence detection of $\mathrm{Hg}^{2+}$. The oligonucleotides used in this work were synthesized and HPLCpurified by Sangon Biotech. Co., Ltd. (Shanghai, China) and their sequences are shown in Table $\mathrm{S} 1$ (Supporting Information). $\mathrm{Cu}\left(\mathrm{NO}_{3}\right)_{2}, \quad \mathrm{Ca}\left(\mathrm{NO}_{3}\right)_{2}, \quad \mathrm{Ni}\left(\mathrm{NO}_{3}\right)_{2} \cdot 6 \mathrm{H}_{2} \mathrm{O}, \quad \mathrm{Fe}\left(\mathrm{NO}_{3}\right)_{3} \cdot 9 \mathrm{H}_{2} \mathrm{O}$, $\mathrm{Zn}\left(\mathrm{NO}_{3}\right)_{2} \cdot 6\left(\mathrm{H}_{2} \mathrm{O}\right), \quad \mathrm{Cr}\left(\mathrm{NO}_{3}\right)_{3} \cdot 9 \mathrm{H}_{2} \mathrm{O}, \quad \mathrm{Ce}\left(\mathrm{NO}_{3}\right)_{3} \cdot 6 \mathrm{H}_{2} \mathrm{O}$, $\mathrm{Al}\left(\mathrm{NO}_{3}\right)_{3} \cdot 9 \mathrm{H}_{2} \mathrm{O}$, and $\mathrm{AgNO}_{3}$ were bought from Sinopharm Group Co., Ltd. (Shanghai, China). All other reagents were of analytical reagent grade. All stock solutions were prepared using ultrapure water $(18.2 \mathrm{M} \Omega \cdot \mathrm{cm})$, which was obtained from a Milli-Q water purification system (Millipore Corp, Bedford, MA).

\section{Apparatus}

All fluorescence measurements were carried out on an F-2700 fluorescence spectrophotometer (Hitachi, Japan) with excitation at $425 \mathrm{~nm}$ and emission at $492 \mathrm{~nm}$ for ThT.

\section{Fluorescent detection for sample solutions}

Firstly, the stock solutions of hairpin probes $\mathrm{H} 1$ and $\mathrm{H} 2$ were, respectively, heated to $95^{\circ} \mathrm{C}$ for $5 \mathrm{~min}$ and then allowed to cool down slowly to room temperature at least for $2 \mathrm{~h}$ to form hairpin structure before use. Meanwhile, $1 \mu \mathrm{L}$ of the T-rich probe (50 $\mathrm{nM}$ final concentration) and $1 \mu \mathrm{L}$ of the initiator probe (50 nM final concentration) were incubated in $74 \mu \mathrm{L}$ of binding buffer ( $25 \mathrm{mM}$ Tris- $\mathrm{HNO}_{3}$, containing $400 \mathrm{mM} \mathrm{NaNO}_{3}, 10 \mathrm{mM}$ $\mathrm{Mg}\left(\mathrm{NO}_{3}\right)_{2}, \mathrm{pH}$ 6.5) for $25 \mathrm{~min}$ at room temperature to form triple-helix molecular switch (THMS).

Secondly, $1 \mu \mathrm{L}$ of the sample solution to be tested (containing $\mathrm{Hg}^{2+}$ or other metal ions) was added to the above-mentioned binding buffer; the mixture was incubated in $37^{\circ} \mathrm{C}$ for $15 \mathrm{~min}$. Then, $10 \mu \mathrm{L}$ of $\mathrm{H} 1$ (200 nM final concentration), $10 \mu \mathrm{L}$ of $\mathrm{H} 2$ (200 nM final concentration) and $2 \mu \mathrm{L}$ of $\mathrm{KNO}_{3}(20 \mathrm{mM}$ final concentration) were added to the above mixture. After incubation at $37^{\circ} \mathrm{C}$ for $2 \mathrm{~h}, 1 \mu \mathrm{L}$ of ThT $(10 \mu \mathrm{M}$ final concentration) was added and the resulting mixture was incubated for another $5 \mathrm{~min}$. The fluorescence emission intensity for the obtained mixture was measured at $492 \mathrm{~nm}$ (excited at 425).

\section{Results and Discussion}

\section{Strategy for $\mathrm{Hg}^{2+}$ detection}

The designed strategy for $\mathrm{Hg}^{2+}$ detection is depicted in Scheme 1. This sensing system includes a triple-helix molecular switch (THMS), two HCR hairpin probes (H1 and H2), and thioflavin $\mathrm{T}$ (ThT). The THMS was designed by the Watson-Crick and Hoogsteen base pairings, and composed of a T-rich probe for the recognition of $\mathrm{Hg}^{2+}$ and an initiator probe. Hairpin 1 is functionalized at its $5^{\prime}$ and $3^{\prime}$ ends with threefourths of the G-quadruplex (domain I) and one-fourth of the G-quadruplex (domain II) sequences respectively. Domain I is linked to sequence IV and partially hybridized with domain III. The domain III in hairpin 1 , which is complementary to the initiator probe, is hybridized with parts of domain IV at the stem region, resulting in a stable hairpin configuration. Hairpin 2 includes at its $5^{\prime}$ and $3^{\prime}$ ends with one-fourth of the G-quadruplex (domain II) and three-fourths of the G-quadruplex (domain I)

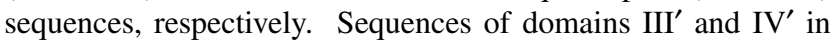
hairpin 2 , which are partially hybridized at the stem region, are complementary to domains III and IV in hairpin 1, respectively. ${ }^{42}$ The THMS is employed as a signal trigger. In the absence of $\mathrm{Hg}^{2+}$, the structure of THMS, $\mathrm{H} 1$ and $\mathrm{H} 2$ remain stable in solution, the selfassembly of ThT/G-quadruplex cannot put into practice due to the fact that the sequence of domain I is locked in the stem region of $\mathrm{H} 1$ and $\mathrm{H} 2$. Since the interactions between ThT and THMS, H1 and $\mathrm{H} 2$ are weak, the fluorescence of the background is low. In the presence of $\mathrm{Hg}^{2+}$, the $\mathrm{T}-\mathrm{Hg}^{2+}-\mathrm{T}$ base pairings resulted in disassembling the THMS and releasing the initiator probe. The released initiator probes hybridize with the domain III in H1, and impel $\mathrm{H} 1$ to be opened so that the singlesstranded domain IV and the conserved three-fourths of the G-quadruplex (domain I) are released. The opened domain IV in $\mathrm{H} 1$ hybridizes with domain $\mathrm{IV}^{\prime}$ in $\mathrm{H} 2$, resulting that domain $\mathrm{III}^{\prime}$ and $\mathrm{I}$ in $\mathrm{H} 2$ are released. The released domain $\mathrm{III}^{\prime}$ in $\mathrm{H} 2$ hybridizes with domain III in the next $\mathrm{H} 1$, where the G-quadruplex fragments (domains I and II) will self-assemble into the G-quadruplex structure, and the next $\mathrm{H} 1$ will be opened. Thus, $\mathrm{H} 1$ and $\mathrm{H} 2$ are cross-opened autonomously and selfassembled into long-chain DNA incorporated with multiple G-quadruplexes, and the formation of the long-chain DNA incorporated with multiple G-quadruplexes depends on the concentration of $\mathrm{Hg}^{2+}$. Because thioflavin $\mathrm{T}(\mathrm{ThT}$ ) can be bound to G-quadruplexe and its fluorescence intensity become 


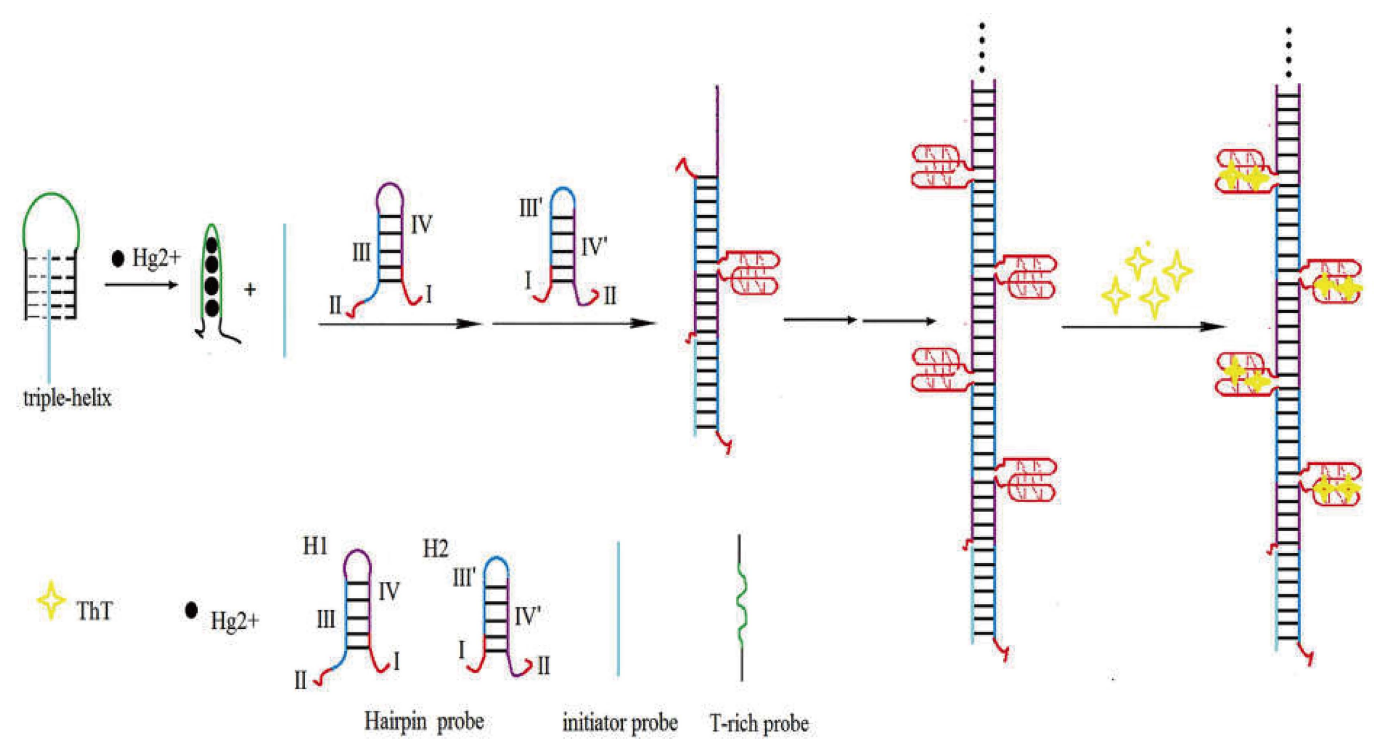

Scheme 1 Schematic drawing for the detection of $\mathrm{Hg}^{2+}$.

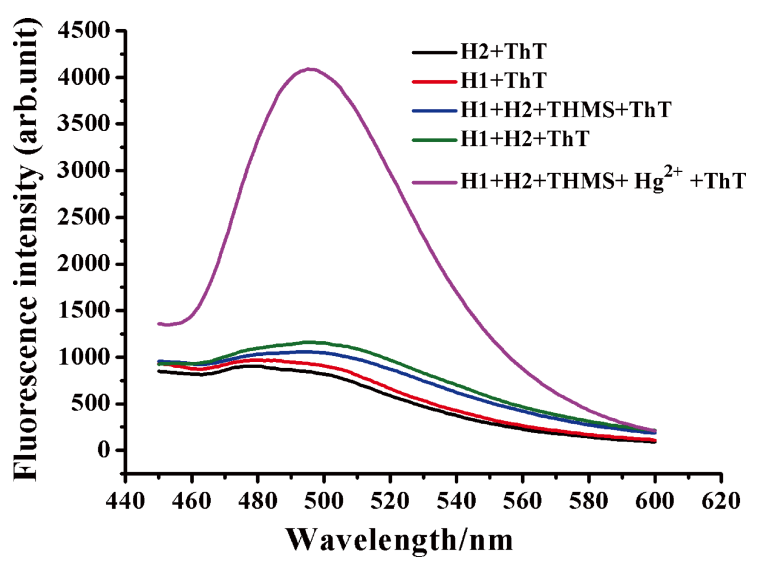

Fig. 1 Fluorescence spectra of from top to bottom $\mathrm{H} 1+\mathrm{H} 2+\mathrm{THMS}^{+} \mathrm{Hg}^{2+}+\mathrm{ThT}, \quad \mathrm{H} 1+\mathrm{H} 2+\mathrm{ThT}, \quad \mathrm{H} 1+\mathrm{H} 2+\mathrm{THMS}+\mathrm{ThT}$, $\mathrm{H} 1+\mathrm{ThT}, \mathrm{H} 2+\mathrm{ThT}$ in Tris-HCl buffer $(25 \mathrm{mM}$, containing $400 \mathrm{mM}$ $\left.\mathrm{NaNO}_{3}, 20 \mathrm{mM} \mathrm{KNO}_{3}, 10 \mathrm{mM} \mathrm{Mg}\left(\mathrm{NO}_{3}\right)_{2}, \mathrm{pH} 6.5\right)$. Excitation: $425 \mathrm{~nm}$; emission: $492 \mathrm{~nm}$.

enhanced, ${ }^{40}$ the long-chain DNA with multiple G-quadruplexes will make the fluorescence intensity of ThT increase greatly. Based on this, the concentration of $\mathrm{Hg}^{2+}$ can be detected by monitoring the fluorescence changes of the solution. To demonstrate the feasibility of this approach, a series of experiments were carried out. As shown in Fig. 1, only H1 or $\mathrm{H} 2$ existed, the fluorescence intensity of the solution was low. In the absence of $\mathrm{Hg}^{2+}$, THMS, $\mathrm{H} 1$ and $\mathrm{H} 2$ remained stable; the fluorescence intensity of the solution was not high. The fluorescence intensity would increase significantly after $\mathrm{Hg}^{2+}$ was brought into the solution. The results indicated that our proposed method could be used to detect $\mathrm{Hg}^{2+}$.

\section{Optimization of the experimental conditions}

For the purpose of maximizing the performance of the $\mathrm{Hg}^{2+}$ assay, we investigated the effect of several parameters on the fluorescence response of the detection platform. The different stem lengths of T-rich probes, the $\mathrm{pH}$ of solution, the concentrations of T-rich probes, $\mathrm{K}^{+}$and ThT were optimized.

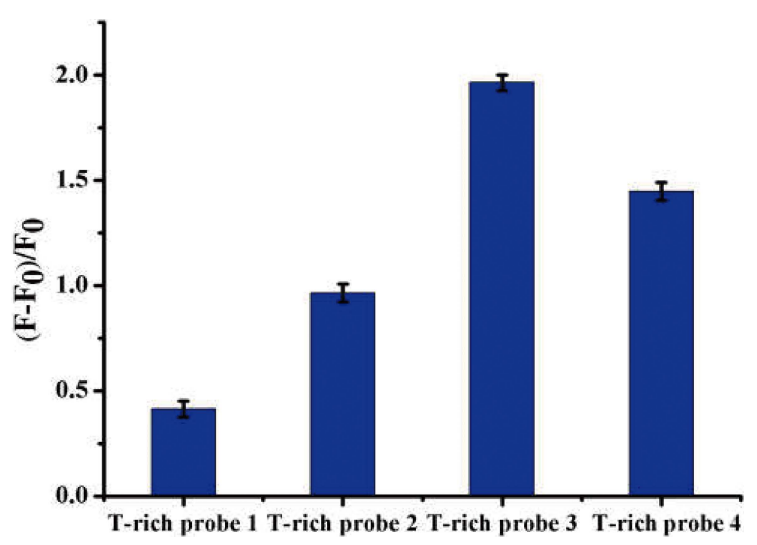

Fig. 2 Fluorescent signal ratio of T-rich probes with different stem lengths (from probes 1 to 4: stem lengths of T-rich were 9, 8, 7 and 6 bases). Condition: $25 \mathrm{mM}$ Tris- $\mathrm{HNO}_{3}(\mathrm{pH} 6.5)$, [H1] $=[\mathrm{H} 2]=$ $200 \mathrm{nM},\left[\mathrm{Hg}^{2+}\right]=10 \mathrm{nM},\left[\mathrm{KNO}_{3}\right]=20 \mathrm{mM}$, [initiator probe $]=[\mathrm{T}-$ rich probe $]=50 \mathrm{nM},[\mathrm{ThT}]=10 \mu \mathrm{M}$

The difficulty level of releasing the initiator probe depends on the stem length of the T-rich probe. ${ }^{36}$ In order to find out the ideal stem length, different T-rich probes with the stem lengths of 6 to 9 bases were investigated. As shown in Fig. 2, the fluorescent signal ratio $\left(\left(F-F_{0}\right) / F_{0}\right.$ was plotted as a function of T-rich probes. $F_{0}$ and $F$ represent the fluorescence intensities at $492 \mathrm{~nm}$ before and after the addition of $\mathrm{Hg}^{2+}$, respectively. T-rich probe 3 with stem lengths of 7 gave the highest fluorescent signal ratio. Thus, we chose T-rich probe 3 with stem lengths of 7 in the further experiment.

A single-stranded DNA molecule rich in guanine $(\mathrm{G})$ can form stable G-quadruplexes under the induction of the $\mathrm{K}^{+}$ion..$^{43}$ In addition, $\mathrm{K}^{+}$can be located at the center cavity between two stacked G-tetrads and coordinates with eight carbonyl oxygen atoms of the $\mathrm{G}$ residues. ${ }^{44}$ The effect of the $\mathrm{K}^{+}$ions concentration on the fluorescence enhancement is shown in Fig. S1 (Supporting Information). As the $\mathrm{K}^{+}$concentration increases to $20 \mathrm{mM}$, the fluorescent signal ratio reaches to the maximum. Thus, the optimal $\mathrm{K}^{+}$ions concentration was chosen to be $20 \mathrm{mM}$. The $\mathrm{pH}$ is a crucial parameter, which is vital to the stability of the 

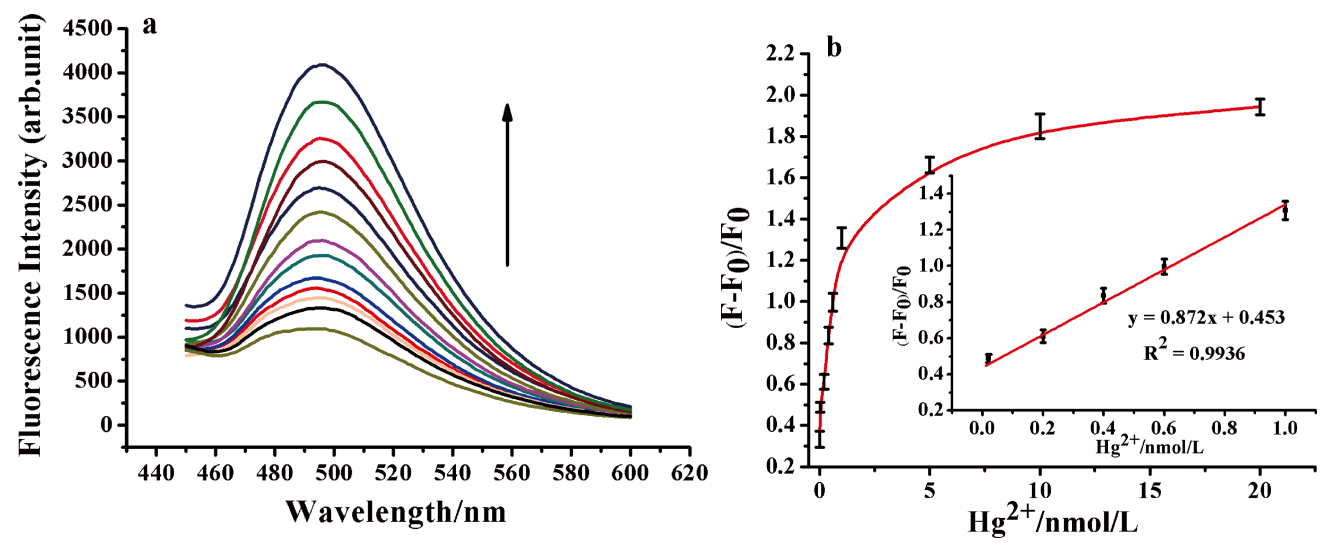

Fig. 3 (a) Fluorescence responses in the presence of different concentrations of $\mathrm{Hg}^{2+}$. From bottom to top: $0,0.02,0.1,0.2,0.4,0.6,1.0,5.0,10.0,20.0,50.0,100.0 \mathrm{nM} \mathrm{Hg}^{2+}$. (b) Relative fluorescence intensity ratio of the THMS-HCR sensing platform in the presence of different concentrations of $\mathrm{Hg}^{2+}$. The inset presents a linear relationship in the concentrations of $\mathrm{Hg}^{2+}$ ranging from 0.02 to $1 \mathrm{nM}$.

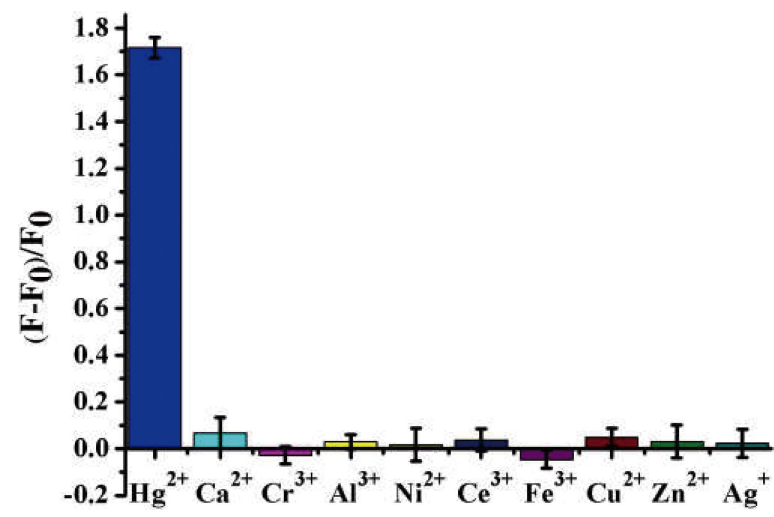

Fig. 4 Selectivity of the $\mathrm{Hg}^{2+}$-sensing. The concentration of $\mathrm{Hg}^{2+}$ is $10 \mathrm{nM}$ and other metal ion is $200 \mathrm{nM}$. Each data were performed in triplicate.

Hoogsteen base pairing to form a stable THMS structure. ${ }^{31}$ Figure S2 (Supporting Information) displays the fluorescence intensity ratio of the sensing platform in different $\mathrm{pH}$ solution. It was observed that the fluorescent ratio rose gradually with the increase of $\mathrm{pH}$ and then reached a peak at 6.5. Thus, the optimal $\mathrm{pH}$ was chosen to be 6.5. As shown in Fig. S3 (Supporting Information), the fluorescent response was increased with the increase of T-rich probe 3 concentrations and reached a plateau at $50 \mathrm{nM}$ of T-rich probe 3 , while keeping T-rich probe 3 and initiator probes with equal proportion. The optimal T-rich probe 3 concentration was chosen to be $50 \mathrm{nM}$. The concentration of ThT can also affect the sensing performance. The result in Fig. S4 (Supporting Information) shows that the fluorescent response enhanced with the increase of the ThT concentration and reached a plateau at $10 \mu \mathrm{M}$ of ThT. The optimal concentration of ThT was chosen to be $10 \mu \mathrm{M}$.

\section{Sensitivity and selectivity}

Under the optimal conditions, we incubated the THMS-HCR sensing platform with various concentrations of $\mathrm{Hg}^{2+}$ $(0-100 \mathrm{nM})$. As shown in Fig. 3a, the fluorescence intensity increased with the increasing concentration of $\mathrm{Hg}^{2+}$. It can be observed in Fig. 3b that the fluorescence enhancement of the sensing platform was proportional to the concentration of $\mathrm{Hg}^{2+}$.
Table 1 Recovery experiments of $\mathrm{Hg}^{2+}$ in tap water by this method

\begin{tabular}{cccc}
\hline Tap water & Added/nM & Found/nM (mean \pm SD) & Recovery, \% \\
\hline Sample 1 & 0.1 & $0.10701 \pm 0.0427$ & 107.01 \\
Sample 2 & 0.5 & $0.50037 \pm 0.0491$ & 100.07 \\
Sample 3 & 1.0 & $0.98135 \pm 0.0109$ & 98.13 \\
\hline
\end{tabular}

a. Mean values and SDs were obtained from three independent experiments.

A linear correlation existed between the fluorescence intensity ratio $\left(\left(F-F_{0}\right) / F_{0}\right)$ and the concentration of $\mathrm{Hg}^{2+}$ in the range of 0.02 to $1 \mathrm{nM}$. The regression equation was $y=0.872 x+0.453$ with a correlation coefficient of 0.993 , the limit of detection (LOD) was $10.2 \mathrm{pM}$, which was relatively low comparable to the recently reported assays (Table S2, Supporting Information).

To demonstrate the selectivity of the proposed assay, a series of metal ions $\left(\mathrm{Cu}^{2+}, \mathrm{Ca}^{2+}, \mathrm{Ni}^{2+}, \mathrm{Fe}^{3+}, \mathrm{Zn}^{2+}, \mathrm{Cr}^{3+}, \mathrm{Ce}^{3+}, \mathrm{Al}^{3+}, \mathrm{Ag}^{+}\right.$, each at $200 \mathrm{nM}$ ) were investigated by this method. As shown in Fig. 4, although the concentrations of $\mathrm{Hg}^{2+}$ were 20-times lower than other metal ions respectively, the fluorescence intensity ratio of $\mathrm{Hg}^{2+}$ was significantly higher than other metal ions. The result indicated excellent selectivity of the presented sensing platform for detection of $\mathrm{Hg}^{2+}$.

\section{Practical application}

To investigate the capability of this method for the determination of $\mathrm{Hg}^{2+}$ in real samples, different concentrations of $\mathrm{Hg}^{2+}$ spiked in tap water were further analyzed. Before detection, the tap water was briefly pretreated. Firstly, the tap water was heated and boiled for $15 \mathrm{~min}$. Then, the tap water sample was filtered through a $0.22-\mu \mathrm{m}$ membrane after the tap water cooled to room temperature. Finally, the processed tapwater sample was diluted 10 fold with $25 \mathrm{mM}$ Tris- $\mathrm{HNO}_{3}$. The treated tap-water sample was firstly analyzed by an atomic absorption spectrophotometer, and our proposed method, respectively; both results indicated that no mercury ions were detected. And then different amounts of $\mathrm{Hg}^{2+}$ were spiked into the sample. The recovery rates for spiked $\mathrm{Hg}^{2+}$ was measured by our proposed method. The results given in Table 1 show that the recovery rates were in the range of 98.13 to $107.01 \%$, indicating that this biosensor was both reliable and practical. 


\section{Conclusions}

In order to detect $\mathrm{Hg}^{2+}$, a novel label-free and highly sensitive fluorescence assay depending on the triple-helix molecular switch (THMS)-induced hybridization chain reaction (HCR) amplification was developed. Two hairpin probes containing the G-quadruplex sequence were used as signal-amplification elements. THMS is composed of a T-rich mercury-specific probe and an initiator probe, designed according to the principle of Watson-Crick and Hoogsteen base pairings. $\mathrm{Hg}^{2+}$ disassembles the THMS and releases the initiator probe, which triggered a successive cross-opening of two hairpins, resulting in the formation of long-chain DNA with multiple G-quadruplex. When thioflavin $\mathrm{T}$ (ThT), a fluorophore, is bound to the G-quadruplex, an obvious fluorescence enhancement will occur. The assay showed a high selectivity to $\mathrm{Hg}^{2+}$ with a detection limit of $10.2 \mathrm{pM}$. Instead of requiring complex experimental techniques, our method is sensitive and selective. In view of these advantages, it is expected that this THMS-HCR sensing platform could be generalized for the detection of $\mathrm{Hg}^{2+}$ ions in a wide range of biological, toxicological, and environmental samples.

\section{Acknowledgements}

This work was supported by National Natural Science Foundation of China (No. 21327009) and Scientific Research Fund of Hunan Provincial Education Department (Nos. 14A012 and 17C0033).

\section{Supporting Information}

Sequences of DNA used in this work, comparison of analytical methods for the detection of $\mathrm{Hg}^{2+}$ and the figures of optimized experimental conditions were listed in Supporting Information. This material is available free of charge on the Web at http:// www.jsac.or.jp/analsci/.

\section{References}

1. J. R. Miller, J. Rowland, P. J. Lechler, M. Desilets, and L. C. Hsu, Water, Air, Soil Pollut., 1996, 86, 373.

2. E. L. Que, D. W. Domaille, and C. J. Chang, Cheminform, 2008, 108, 1517.

3. F. A. Cotton, G. Wilkinson, C. A. Murillo, and M. Bochmann, "Advanced Inorganic Chemistry", 1999, Wiley, New York.

4. D. Mozaffarian and E. B. Rimm, J. Am. Med. Assoc., 2006, 296, 1885.

5. D. Xiang, K. Zhai, Q. Sang, B. Shi, and X. Yang, Anal. Sci., 2017, 33, 275.

6. E. M. Nolan and S. J. Lippard, Cheminform, 2008, 39, 3443.

7. Y. Wang, F. Yang, and X. Yang, Biosens. Bioelectron., 2010, 25, 1994

8. H. Wang, J. Chen, Y. Hong, K Lv, M Yu, and P. S. Zhang, Anal. Sci., 2017, 33, 591.

9. J. Huang, X. Gao, and J. Jia, Anal. Chem., 2014, 86, 3209.

10. H. Shoaee, M. Roshdi, and N. Khanlarzadeh, Spectrochim. Acta, Part A, 2012, 98, 70.

11. N. Bansal, J. Vaughan, and A. Boullemant, Microchem. J., 2014, 113, 36.

12. N. A. Panichev and S. E. Panicheva, Food Chem., 2015, $166,432$.

13. X. Chen, C. Han, H. Cheng, Y. Wang, and J. Liu, J.
Chromatogr. A, 2013, 1314, 86.

14. E. Vassileva, I. Wysocka, and M. Betti, Microchem. J., 2014, 116, 197.

15. A. T. Townsend, K. A. Miller, S. Mclean, and S. Aldous, $J$. Anal. At. Spectrom., 1998, 13, 1213.

16. Q. Zhou, X. An, and K. Zhao, J. Chromatogr. A, 2014, $1360,76$.

17. Z. Gao and X. Ma, Anal. Chim. Acta, 2011, 702, 50.

18. X. Yuan, G. Yang, Y. Ding, X. Li, X. Zhan, and Z Zhao, Spectrochim. Acta, Part B, 2014, 93, 1.

19. L. W. Liu, H. L. Zheng, C. Yang, L. Xiao, and Z. L. Yilan, Spectrosc. Lett., 2014, 47, 604.

20. W. B. Zhang, C. X. Sun, and X. A. Yang, Anal. Methods, 2014, 6, 2876.

21. A. Ono and H. Togashi, Angew. Chem., Int. Ed., 2004, 43, 4300.

22. S. M. Jia, X. F. Liu, P. Li, D. M. Kong, and H. X. Shen, Biosens. Bioelectron., 2011, 27, 148.

23. X. Huang, Y. Hao, H. Wu, Q. Guo, and L. Guo, Sens. Actuators, B, 2014, 191, 600.

24. S. Tang, P. Tong, M. Wang, J. Chen, and G. Li, Chem. Commun., 2015, 51, 15043.

25. T. Bao, W. Wen, X. Zhang, Q. Xia, and S. Wang, Biosens. Bioelectron., 2015, 70, 318.

26. Y. Zhang, G. M. Zeng, L. Tang, Y. P. Li, and Z. M. Chen, RSC Adv., 2014, 4, 18485.

27. D. Tan, Y. He, X. Xing, Y. Zhao, H. Tang, and D. Pang, Talanta, 2013, 113, 26.

28. L. Guo, N. Yin, D. Nie, J. Gan, M. Li, F. Fu, and G. Chen, Analyst, 2011, 136, 1632.

29. R. M. Dirks and N. A. Pierce, Proc. Natl. Acad. Sci. U. S. A., 2004, 101, 15275.

30. L. N. Wang, F. Y. Liu, N. Sui, M. H. Liu, and W. W. Yu, Microchim. Acta, 2016, 183, 2855.

31. E. H. Xiong, X. H. Zhang, Y. Q. Liu, J. W. Zhou, P. Yu, and J. H. Chen, Anal. Methods, 2016, 8, 2106.

32. N. Sui, K. Wang, L. N. Wang, F. Y. Xie, M. H. Liu, and W. W. Yu, Sens. Actuatorts, B, 2017, 245, 568.

33. M. Salunkhe, T. Wu, and R. L. Letsinger, J. Am. Chem. Soc., 1992, 114, 8768.

34. K. M. Vasquez and P. M. Glazer, Q. Rev. Biophys., 2002 , $35,89$.

35. J. Zheng, J. S. Li, and Y. Jiang, Anal. Chem., 2011, 83, 6586.

36. J. Zheng, Y. H. Nie, Y. P. Hu, J. S. Li, and R. H. Yang, Chem. Commun., 2013, 49, 6915

37. T. X. Chen, F. Ning, H. S. Liu, K. F. Wu, and W. Li, Chin. Chem. Lett., 2017, 28, 1380

38. M. Ramezani, D. N. Mohammad, P. Lavaee, K. Abnous, and T. S. Mohammad, Biosens. Bioelectron., 2015, 70, 181.

39. Q. Liu, J. Liu, D. He, T. Qing, and X. He, RSC Adv., 2016, 6, 90310 .

40. J. Mohanty, N. Barooah, V. Dhamodharan, S. Harikrishna, and P. I. Pradeepkumar, J. Am. Chem. Soc., 2013, 135, 367.

41. F. A. Renaud, A. Guédin, A. Bedrat, L. A. Yatsunyk, and J. L. Mergny, Nucleic Acids Res., 2014, 42, 376.

42. S. Shimron, F. Wang, R. Orbach, and I. Willner, Anal. Chem., 2012, 84, 1042.

43. R. K. Saiki, D. H. Gelfand, S. Stoffel, and S. J. Scharf, Science, 1988, 239, 487.

44. D. Sen and W. Gilbert, Nature, 1990, 344, 410.

45. Y. Wang, L. Jiang, Q. Leng, Y. Wu, and X. He, Biosens. Bioelectron., 2015, 77, 914.

46. L. Chen, J. Li, and L. Chen, ACS Appl. Mater. Interfaces, 2014, 6, 15897.

47. K. Srinivasan, K. Subramanian, K. Murugan, and K. Dinakaran, Analyst, 2016, 141, 6344. 